Ebisu Ebisu

Études japonaises Études japonaises

47 | printemps-été 2012

Catastrophes du 11 mars 2011, désastre de

Fukushima : fractures et émergences

\title{
Communautés de quartier et associations : le retour du local après le 11 mars 2011
}

The Revival of Local Neighbourhood Communities and Associations After March 11 th

町内会とコミュニテイー2011年3月11日のの地域回帰

Patricia Marmignon

\section{OpenEdition}

1 Journals

Édition électronique

URL : http://journals.openedition.org/ebisu/459

DOI : 10.4000/ebisu.459

ISSN : 2189-1893

Éditeur :

Institut français de recherche sur le Japon (UMIFRE 19 MAEE-CNRS), Maison franco-japonaise

Édition imprimée

Date de publication : 1 juin 2012

Pagination : 215-221

ISSN : 1340-3656

\section{Référence électronique}

Patricia Marmignon, «Communautés de quartier et associations : le retour du local après le 11 mars 2011 », Ebisu [En ligne], 47 | printemps-été 2012, mis en ligne le 03 avril 2014, consulté le 22 avril 2019 URL : http://journals.openedition.org/ebisu/459 ; DOI : 10.4000/ebisu.459 


\title{
Communautés de quartier et associations Le retour du local après le 11 mars 2011
}

\author{
Patricia MARMIGNON
}

Les communautés de quartier et les associations, plus récentes, ont évolué dans l'histoire. Ces dernières sont apparues à la fin des années 1960, mais se sont développées et ont fait l'objet d'une législation après le séisme de Kobe (dit Hanshin Awaji daishinsai 阪神・淡路大震災) de 1995. Elles semblaient représenter un pas vers une reconnaissance du droit de l'individu dans les processus de décision relatifs à l'urbanisation. Mais qu'en est-il depuis le 11 mars?

\section{L'évolution des communautés de quartier}

Les " communautés de quartier " évoluèrent au fur et à mesure des événements, des ruptures, des catastrophes. C'est ainsi que les chōnaikai 町内会 prirent véritablement leur envol dans les grandes villes, après le grand séisme du Kantō 関東 de 1923. Le département de l'éducation de la ville de Tokyo établit en 1924 les "procédés réglementaires des conseils ", chōkai kiyaku $y \bar{o} r y \bar{o}$ 町会規約要領, régulant les $c h \bar{o}$ 町 (quartiers) pour la réorganisation, la reconstruction, l'assistance et la sécurité. Des communautés de quartier se constituèrent successivement à Yokohama, à Nagoya ou à Osaka. Elles

Patricia Marmignon est chercheuse associée (AUS/UMR 7218 LAVUE/CNRS), post-doctorante (CRJ/EHESS), qualifiée maître de conférences en aménagement de l'espace/urbanisme, architecte et docteur de l'EHESS en études urbaines. 
assuraient un rôle de formation communautaire et de transmission des informations officielles, donc de contrôle social à chaque catastrophe.

Les chōnaikai sont un produit de la modernité dans le prolongement du chien 地縁 (lien de sol) ${ }^{1}$. De type kyōdōtai 共同体 (gemeinschaft, communauté), ces communautés de quartier ont comme unité l'ie 家 (la maison) et non l'individu. Elles ne sont point fondées « sur la libre association d'individus égaux visant un but précis, mais sur un collectivisme diffus niant l'individu " (Berque 2004). Les chōnaikai sont à considérer comme des organisations liées par l'habiter, l'habitat et à des activités lucratives ou non. Elles s'inscrivent dans un système hiérarchisé qui part du haut.

Après l'incident de Mandchourie en 1931, elles servirent à l'organisation pratique du Mouvement de mobilisation générale de l'esprit patriotique (Kokumin seishin sōdōin undō 国民精神総動員運動), par l'intermédiaire du gouvernement local sous l'égide du Naimushō 内務省 (ministère de l'Intérieur). L'étatisation de communautés de quartier s'intensifia à partir de 1940 avec la mise en place des tonarigumi 隣組 (groupes de voisinage). De ce fait, malgré la volonté du Naimushō de maintenir les chōnaikai après la défaite, elles furent " abolies » en 1947 par décret (tout comme le Naimushō), car considérées comme anti-démocratiques.

Rétablies par le traité de paix en 1952, les chōnaikai impliquent la plupart des habitants. Leurs fonctions sont diverses. Elles concernent la sécurité, la cogestion des équipements et du patrimoine du quartier, comme la gestion et l'entretien de la voirie, des espaces verts, de l'éclairage public, l'information ou l'organisation de fêtes locales. Elles sont à l'origine de conventions architecturales locales (kenchiku kyōtei 建築協定). Leurs activités évoluent aussi vers l'aide aux personnes âgées, aux handicapés, la gestion des déchets. Leur rôle a d'abord consisté à participer à des enquêtes et à des audiences publiques à la demande des autorités. Leur intervention dans les processus de prise de décision s'est aujourd'hui institutionnalisée sous la forme d'une concertation (kyōgi 協議) systématique (Marmignon 2011).

1. Dès le $\mathrm{XV}^{\mathrm{e}}$ siècle, des groupes unis pour la protection du voisinage apparaissent au sein des chō. Puis, au Xvi siècle, des groupes de cinq à dix maisonnées, goningumi 五人 組, jūningumi十人組, se constituent. Ils assurent un contrôle et une assistance mutuelle dans un système hiérarchisé, à l'image des exploitations agricoles, des communautés villageoises, mura 村, composées de maisons, ie. À partir du XVII ${ }^{\mathrm{e}}$ siècle, aux $c h \bar{o}$ sont associés des métiers. 
Elles connaissent un nouveau souffle depuis 2004 grâce aux conseils de quartier (chiiki jichi ku 地域自治区) créés par la loi fondamentale des collectivités autonomes (Takamura 2009). Ils se composent d'anciens élus, de représentants des communautés de quartier et d'associations locales, ainsi que de bénévoles comprenant des professionnels et des universitaires. Ces conseils ont pour fonction de participer au processus de décision des politiques locales, de coordonner les services publics de proximité, et d'élaborer le plan local de collaboration entre les municipalités et les habitants. Mais, sur les côtes Nord-Est de l'île de Honshū 本州, depuis le 11 mars 2011, le tsunami a en partie détruit les chōnaikai et le milieu humain.

\section{Les komyuniti (associations) : vers plus de droit ?}

Depuis 1968, les communautés de quartier peuvent être relayées par, ou coopérer avec des associations (komyuniti コミュニテイ) (Marmignon 2010, 2011). Leur préoccupation centrale devient celle de l'habiter en zone urbaine. Elles symbolisent, avec la nouvelle loi d'urbanisme de 1968 qui introduit l'audience publique (kōchōkai 公聴会), un tournant vers une autonomie locale (chihōjichi 地方自治) (Marmignon 2011). On s’est mis à dire jichikai 自治会 dans certaines régions, plutôt que chōnaikai.

Komyuniti est un anglicisme issu d'une réaction du gouvernement face aux mouvements d'habitants (jümin undō 住民運動) des années 1965-1975. Ces derniers se dressèrent, en raison de la pollution, contre les gouvernements locaux, puis contre le gouvernement central, la fédération patronale (Keidanren 経団連) et les milieux d'affaires. Quatre grands procès contre la pollution industrielle marquèrent la vie politique entre 1971 et 1973 et correspondirent à la fin de la période de haute croissance ( $k \bar{o} d o$ seichō 高度 成長, 1955-1973). On parle alors de komyuniti zukuri コミュニテイづくり, de création de komyuniti.

Le terme komyuniti que l'on peut traduire par " association " en se référant à MacIver (1917) (Köjien 2004), et qui prend en compte l'être social, ne fut qu'une récupération des mouvements d'habitants par et pour le gouvernement. Le premier texte gouvernemental abordant cette notion est celui d'une consultation à une réunion d'enquête de l'assemblée délibérante sur les conditions de vie de la population (kokumin seikatsu shingikai chōsabu $k a i$ 国民生活審議会調査部会) auprès du Premier ministre Satō Eisaku 
佐藤栄作 (1901-1975), en janvier de la 43e année de l'ère Shōwa (1968). Cette discussion était intitulée "Des mesures afin d'assurer au peuple une vie saine en réponse aux conditions de vie en mutation qui accompagnent l'essor de croissance économique dans la société " ("Keizai shakai no seichö hatten ni tomonai henka shitsutsu aru sho jōken ni taiō shite kenzen na kokumin seikatsu o kakuho suru tame no hōsaku " 経済社会の成長発展 に伴い変化しつつある諸条件に対応して健全な国民生活を確保するための方策) (Takemura 1978).

Au cours de cette réunion, la question de la formation de komyuniti fut examinée selon trois axes relatifs aux conditions de vie de la population sur le long terme, aux personnes âgées et aux loisirs. De là fut formé un comité restreint (shō iinnkai 小委員会) sur la question des komyuniti, qui publia en 1969 les premiers bulletins officiels sur ce sujet. Ces bulletins traitaient de la nécessité des komyuniti, des mesures à prendre pour leur formation en remplacement des communautés locales (chiiki kyödōtai 地域共同体).

Les komyuniti se sont particulièrement développées depuis le grand séisme de Hanshin Awaji de 1995. L'autonomie des habitants (jümin jichi 住民自 治) et le bénévolat (borantia katsudo ボランテイア活動) ont émergé et se sont institutionnalisés à la fin des annés 1990. En 1998, la loi sur les associations (équivalent de la loi de 1901 en France) est promulguée : loi NPO/loi pour l'accélération des activités à but non lucratif (Enu pī ō hō/tokutei hieiri katsudō sokushin hō NPO法/特定非営利活動促進法). Elle vient reconnaître comme personnes morales ces nouveaux acteurs (Marmignon 2010, 2011). Leur rôle est, en principe, complémentaire de celui du gouvernement et des entreprises, mais s'accroît depuis le 11 mars 2011.

\section{Après le 11 mars : « la reconstruction de komyuniti »}

Depuis le 11 mars, le terme komyuniti semble évoluer. Il devient plus général et semble intégrer les différentes associations, aussi bien que de futurs jichikai 自治会 et des corporations de métiers, d'agriculteurs ou de pêcheurs. Mais, s'il semblait démontrer un certain droit de l'individu et une autonomie locale, il manifeste aussi une absence des pouvoirs publics. C'est ainsi que les maîtres mots sont « la reconstruction de komyuniti (komyuniti fukkō コミュニ テイ復興) », « la reconstruction de l'être humain (ningen fukkō 人間復興) ». 
La décentralisation et le rôle croissant accordé aux localités se confirment depuis 1968. Le déclin naturel de la population se poursuit dans les villages depuis les années 1980 (Miyairi 2011) étant donné leur désertion et le vieillissement de la population. La rétraction urbaine, le retour vers une ville compacte est entamé depuis les années 1990 (Marmignon 2010). Depuis les années 2000, on parle de développement durable, jizoku kanō-na kaihatsu 持続可能な開発. La reconstruction, suite à cette triple catastrophe, séisme, tsunami et accidents nucléaires, doit tenir compte de ces tendances. Mais, la reconstruction par qui ?

Depuis le grand séisme de l'Est du Japon, au niveau local, les komyuniti sont les principaux acteurs dans l'urgence. À moyen terme, les collectivités locales (jichitai 自治体) prendront des mesures concertées pour le développement de la région. Et, sur le long terme, l'État devrait s'interroger sur un nouveau modèle national tourné vers le développement durable². Cependant, dès à présent, des aides de l'État sont attendues, car aujourd'hui seules les dettes demeurent (Miyairi 2011).

Depuis le 11 mars 2011, des komyuniti regroupent habitants, bénévoles, spécialistes du bien-être social, de la santé, juristes, avocats, conseillers, éducateurs, architectes, urbanistes, historiens ou encore artistes. Elles ont un rôle de soutien et de consultation (kyōgi), et enquêtent sur les besoins. Elles offrent nourriture et vêtements, produits de première nécessité et soins médicaux d'urgence. Elles informent et transmettent les messages des réfugiés, voire des objets retrouvés (Sawami 2011). Le tout est de retisser les liens sociaux et de recréer des communautés locales. Elles participent aux traitements des gravats, à la remise en état des terres, à la réfection rapide des habitations, à la construction de logements temporaires réutilisables et tournés vers des espaces collectifs, des jardins partagés. Il y a 90000 sansabris et la demande de logements est grande.

Les komyuniti permettent aussi la reconstruction des liens de sol et la territorialisation des corporations, le rétablissement des métiers locaux. Elles

2. Entretien avec Sugi Takako 杉貴子, architecte et présidente de l'AFJAD, Association franco-japonaise de l'architecture et du design, organisatrice du colloque "Ville et architecture après le 11 mars. Comment les architectes régénèrent-ils le local ?" ("San ten ichi ichi ato no kenchiku toshi. Kenchikuka tachi wa chiiki o dō saisei shiyö toshite iru no ka? » 3.11 後の建築・都市一建築家たちは地域をどう再生しようとしているのか?), à l'ENSA Paris-Malaquais les 29 et 30 mars 2012 et à la MCJP le 31. 
participent à la mise en place de commerces temporaires et à la reconstitution d'un parcellaire, comme en 1923, de terres communales qui seront revendues par la suite aux propriétaires. Elles organisent avec l'aide des municipalités la distribution d'emplois journaliers, par le biais d'une assemblée, comme Seki Hajime 関一 (1873-1935) l'avait fait, suite aux émeutes du riz de 1918. Des quartiers sont affectés à des activités agricoles ou aquicoles, et des assemblées d'habitants, de travailleurs ou d'exploitants sont créées ou redéfinies.

Depuis le 11 mars, nous assistons à la confirmation de l'importance croissante accordée au local. Mais, nous ne pouvons dire s'il s'agit d'une évolution à caractère positif, d'un tournant vers une autonomie et pour une meilleure concertation. La reconstruction du Tohoku, semble-t-il, ne peut passer que par une collaboration entre tous les acteurs, locaux, régionaux et nationaux. Et, les questions majeures qui demeurent aujourd'hui, concernent la transparence et les aides de l'État, la décentralisation des activités, ainsi que la participation des habitants aux décisions politiques.

20 novembre 2011 (finalisé le 12 avril 2012) 


\section{Bibliographie}

\section{BERQUE Augustin, 2004}

Le sens de l'espace au Japon.

Vivre, penser, bâtir, Paris, Arguments.

IWASAKI Nobuhiko 岩崎信彦 et al., 1989

Chōnaikai no kenkyū 町内会の研究

(Recherches sur les communautés

de quartiers), Tokyo, Ochanomizu shobō

御茶の水書房.

\section{McIVER Robert Morrison,} 2010 [éd. or. 1917]

Community, a Sociological Study. Being an Attempt To Set Out the Nature and Fundamental Laws of Social Life, 30 juin, Lexington, Cornel University Library Digital Collections.

\section{MARMIGNON Patricia, 2010}

La création de l'urbain. Paysage urbain et socialité à Osaka depuis Meiji (1868), Sarrebruck, EUE.

\section{MARMIGNON Patricia, 2011}

"La concertation au Japon : autonomie locale, collaboration et participation ", in UR CAUE Languedoc-Roussillon, «CAUE \& Concertation... pour une vraie participation! », Site du Pont du Gard, Université d'été CAUE, 8 septembre. Accessible via Internet : <http:// www.mesologiques.com/2011/10/ la-concertation-au-Japon-autonomie. html>.

\section{MIYAIRI Kōichi 宮入興—, 2011}

« Higashi Nihon dai shinsai to fukkō no katachi. Seichō kaihatsu gata fukkō kara ningen to kizuna no fukkō e » 東日本大
震災と復興のかたち——成長・開発型復興 から人間と絆の復興へ (Le grand séisme de l'Est du Japon et les formes de la reconstruction. De la reconstruction par la croissance et par le développement, à la reconstruction par les hommes et par la solidarité), Sekai 世界, août, $820: 43-55$.

SAWAMI Ryōko 沢見涼子, 2011 « Kokyō o hanarete. Hinansha to borantia, hantoshi no kiseki » 故郷を離れて——避難者とボランテイア. 半年の軌跡 (S'éloigner du pays natal. Six mois du parcours des réfugiés et des bénévoles), Sekai 世界, octobre, 822 : 62-72.

TAKAMURA Gakuto, 2009 «Japon : participation des habitants... au service public ", in TOURNON Jean (dir.), La république antiparticipative. Les obstacles à la participation des citoyens à la démocratie locale, Paris, L'Harmattan, pp. 145-155.

TAKEMURA Yasuharu 竹村保治, 1978 "Ōsaka-shi no "komyuniti zukuri" ni tsuite : kiroku to jakkan no kōsatsu » 大阪市の「コミュニテイづくり」につい て—記録と若干の考察 (À propos de la création de komyuniti dans la ville d'Osaka. Des actes et quelques observations), Toshi mondai kenkyū 都市問題研究, juillet, 30 (7) : 77-95. 